\title{
Modeling of COVID-19 Infection per 1 Million Population in Indonesia
}

\author{
Anton Rahmadi ${ }^{1}$, Ronny Isnuwardana ${ }^{23}$, Swandari Paramita ${ }^{12^{*}}$ \\ ${ }^{1}$ Center of Excellence for Tropical Studies, Mulawarman University, Samarinda, Indonesia \\ ${ }^{2}$ Department of Community Medicine, Faculty of Medicine, Mulawarman University, Samarinda, \\ Indonesia \\ ${ }^{3}$ Doctoral Program in Clinical Epidemiology, Faculty of Medicine Ramathibodi Hospital, Mahidol \\ University, Bangkok, Thailand
}

*Corresponding Author: s.paramita@fk.unmul.ac.id

\section{INTRODUCTION TO DATA SET}

Aim: We aim to predict the number of COVID-19 infections per 1 million population in Indonesia. This is to help the Indonesia Government to decisively take exact measure in preventing and fighting the COVID-19 in Indonesia, as well as to predict the number of logistics and human resources required in fighting this dangerous disease.

Method: The models include (A) Population Density per Km, (B) Contagion per $1 \mathrm{M}$ population, (C) Income per Capita, (D) Health Care Index, (E) Energy Index, (F) A*D (in thousands), (G) Elderly Population, (H) G/D, (I) Years of Schooling, (J) Public Trust in Politicians. Eleven countries were selected to calculate the best correlation of all parameters, therefore can be applied to estimate contagion per $1 \mathrm{M}$ population in Indonesia. These countries include Iran, France, Italy, Netherland, Germany, China, UK, USA, Spain, Malaysia, and Singapore.

Key findings: As of $23^{\text {rd }}$ March 2020, Indonesian daily trajectory follows $3^{\text {rd }}$ order polynomial with [daily number of COVID-19 positive] $=0,0891$ (days) $^{3}-0,8385$ (days) $^{2}+2,5223$ (days) $+0,458$ with $R^{2}$ $=0,9966$. The best model is produced from Public Trust to Politicians vs Contagion per $1 \mathrm{M}$ population with correlation of 0.898 . From the linear graph, COVID-19 per $1 \mathrm{M}$ population = (trust 5.2558)/0.1227, we estimate the current peak of positive COVID-19 per $1 \mathrm{M}$ population in Indonesia to be 299 persons.

Recommendations: Models from eleven countries produce a typical spread of COVID-19 have a strong correlation with (1) level of trust in government or community leaders, Moderately correlated with (3) elderly population and (4) health service index and weakly correlated with (5) income per capita, population density, and (6) education level. To avoid 299 positive COVID-19 per $1 \mathrm{M}$ population in Indonesia the best strategy is to work together with community leaders and strong influencers so that the people can follow government recommendation i.e. to stay at home, to work from home, and to avoid the crowd.

Keywords: COVID-19, Indonesia, Public Trust to Politicians, Contagion per 1M population 
Graph 1. Daily number of confirmed COVID-19 cases in Indonesia

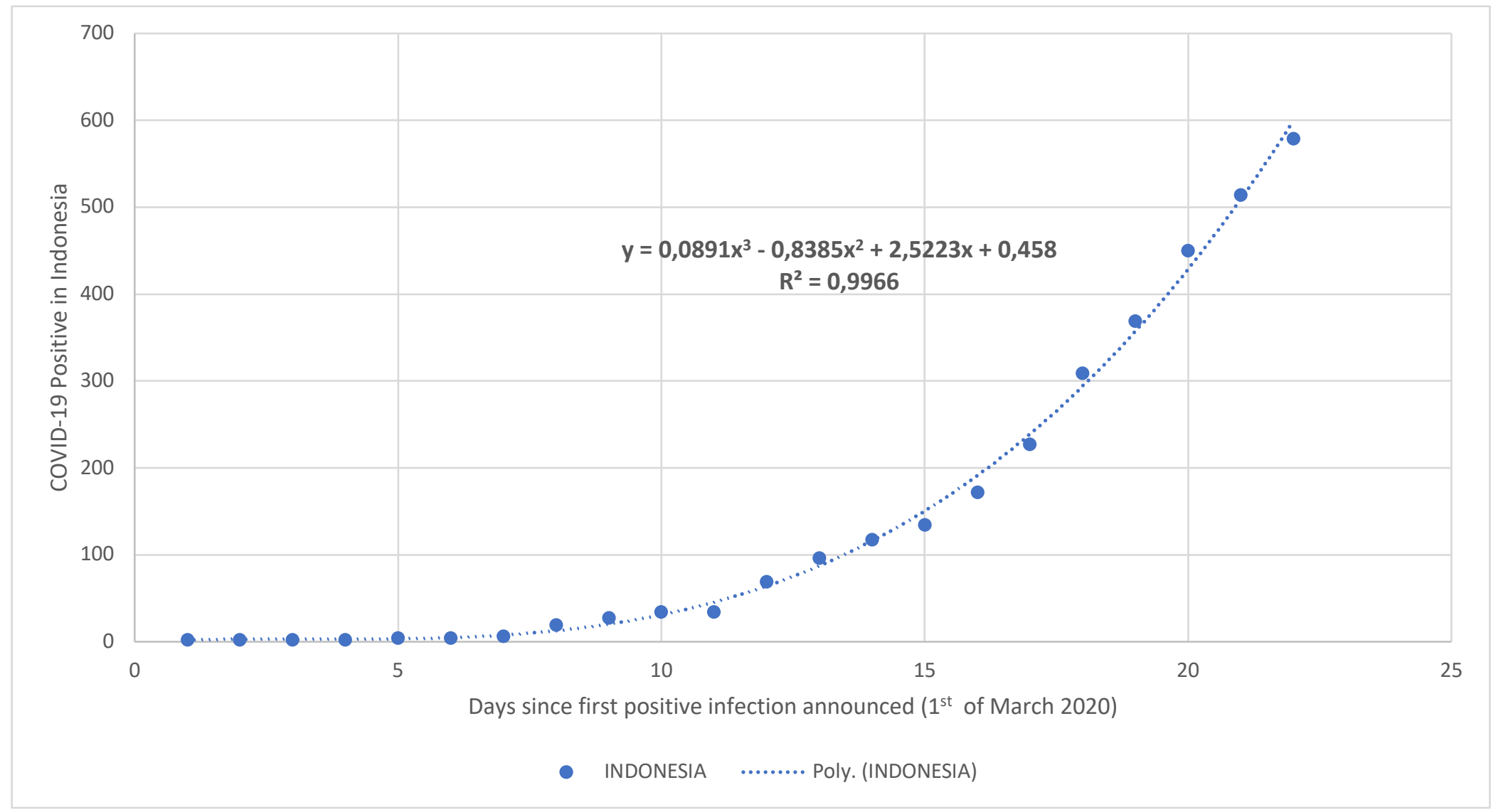


Table 1. Possible predictors in the determination of contagion per $1 \mathrm{M}$ population in Indonesia

\begin{tabular}{|c|c|c|c|c|c|c|c|c|c|c|}
\hline Country & $\begin{array}{c}\text { A } \\
\text { Population } \\
\text { Density per } \\
\text { Km }\end{array}$ & $\begin{array}{c}\text { B } \\
\text { Contagion per } \\
\text { 1M pop. }\end{array}$ & $\begin{array}{c}\text { C } \\
\text { Income per } \\
\text { Capita }\end{array}$ & $\begin{array}{c}\text { D } \\
\text { Health Care } \\
\text { Index }\end{array}$ & $\begin{array}{c}\text { E } \\
\text { Energy } \\
\text { Index }\end{array}$ & $\begin{array}{c}F \\
A * D \\
(000)\end{array}$ & $\begin{array}{c}\text { G } \\
\text { Elderly } \\
\text { Population }\end{array}$ & $\begin{array}{c}H \\
G / D\end{array}$ & $\begin{array}{c}\text { I } \\
\text { Years of } \\
\text { Schooling }\end{array}$ & $\begin{array}{c}\text { J } \\
\text { Public Trust in } \\
\text { Politicians }\end{array}$ \\
\hline Indonesia* & $\begin{array}{r}1121 \\
\text { (Java) }\end{array}$ & 299* & 2520.9 & 60 & 64.1 & 67.8 & 6.44 & 0.11 & 8 & 42 \\
\hline Iran & 134 & 258 & 5503.1 & 52 & 63.6 & 67.8 & 8.7 & 0.17 & 15 & 49 \\
\hline France & 122 & 245 & 41,080 & 80 & 81 & 9.76 & 17.95 & 0.22 & 11 & 44 \\
\hline Italy & 205 & 978 & 33,730 & 67 & 77 & 13.65 & 21.25 & 0.32 & 10 & 122 \\
\hline Netherland & 511 & 245 & 51,260 & 75 & 78 & 38.15 & 17.09 & 0.23 & 12 & 7 \\
\hline Germany & 237 & 297 & 47,090 & 73 & 79 & 17.38 & 21.45 & 0.29 & 14 & 13 \\
\hline China & 145 & 56 & 9,389 & 64 & 64 & 9.35 & 9 & 0.14 & 8 & 27 \\
\hline UK & 274 & 84 & 43,160 & 74 & 82 & 20.40 & 18 & 0.24 & 13 & 17 \\
\hline USA & 94 & 105 & 60,200 & 69 & 78 & 6.51 & 16 & 0.14 & 12 & 16 \\
\hline Spain & 92 & 640 & 30,370 & 79 & 77 & 7.26 & 17 & 0.22 & 12 & 104 \\
\hline Malaysia & 96 & 40 & 10,590 & 68 & 69 & 6.54 & 18 & 0.26 & 10 & 29 \\
\hline Singapore & 7953 & 78 & 58,770 & 71 & 71 & 563.39 & 10 & 0.14 & 12 & 1 \\
\hline $\begin{array}{l}\text { CORRELATION } \\
\text { (except Indonesia) }\end{array}$ & -0.225 & & -0.029 & 0.068 & 0.271 & -0.230 & -0.421 & 0.573 & -0.034 & 0.898 \\
\hline
\end{tabular}

* optimized case predicted based on Graph 2. 


\section{Graph 2. Four models to predict the number of Indonesia's COVID-19 contagion per 1M population}
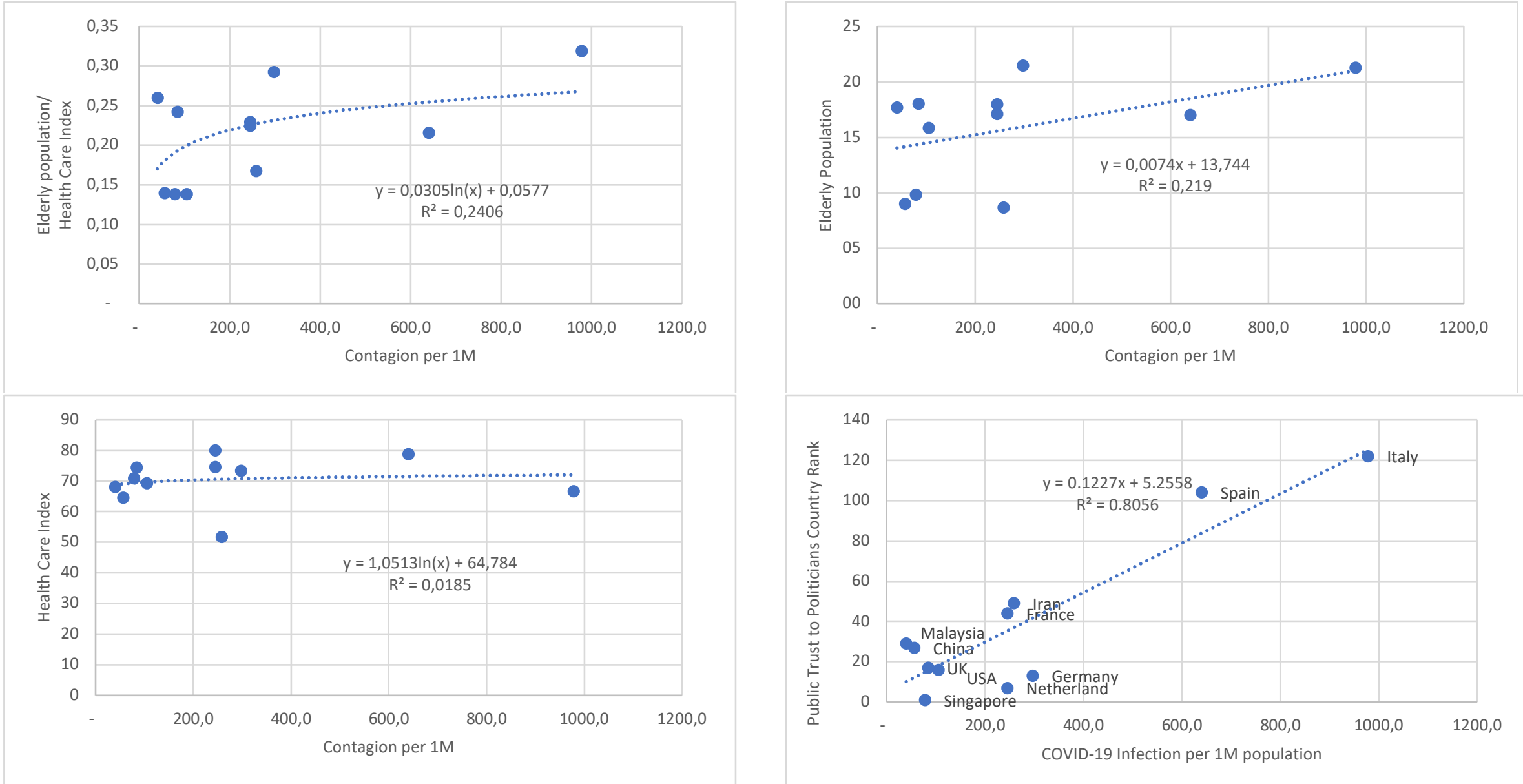